\title{
Breath isoprene during acute respiratory exacerbation in cystic fibrosis
}

\author{
L.T. McGrath*, R. Patrick ${ }^{+}$, P. Mallon ${ }^{\#}$ L. Dowey", B. Silke*, W. Norwood*, S. Elborn ${ }^{\#}$
}

Breath isoprene during acute respiratory exacerbation in cystic fibrosis. L.T. McGrath, R. Patrick, P. Mallon, L. Dowey, B. Silke, W. Norwood, S. Elborn. (C)ERS Journals Ltd 2000. ABSTRACT: Patients with cystic fibrosis (CF) experience a combination of chronic systemic oxidative stress, generation of free radicals in the lungs due to a hyperimmune response and a diminished ability to scavenge free radicals secondary to malabsorption and increased consumption. The authors asked the question, "Does breath isoprene content reflect systemic oxidative stress?"

The study involved $12 \mathrm{CF}$ patients and 12 matched healthy controls. The patients were sampled during acute respiratory exacerbation (increased respiratory symptoms, reduction in forced expiratory volume (FEV1) of $>10 \%$, and a decision to treat with intravenous antibiotics) and after two weeks of antibiotic treatment. Blood samples were examined for markers of oxidative stress. Breath samples were analysed for isoprene content.

Malondialdehyde (MDA), erythrocyte membrane polyunsaturated fatty acids, protein sulphydryls and protein carbonyls all showed evidence of increased oxidative stress which was moderated by antibiotic treatment. Breath isoprene production rate was significantly lower in patients during exacerbation than in controls with a mean difference of $-39(95 \%$ confidence interval (CI) $-11-57) \mathrm{pmol} \cdot \mathrm{min} \cdot \mathrm{kg}^{-1}$ and increased to normal values following treatment (mean change 63 (95\% CI 42-84) $\mathrm{pmol} \cdot \mathrm{min} \cdot \mathrm{kg}^{-1}$ ).

In conclusion, breath isoprene cannot be considered a reliable marker of oxidative stress.

Eur Respir J 2000; 16: 1065-1069.

\begin{abstract}
*Dept of Therapeutics and Pharmacology, +Dept of Chemistry, The Queen's University of Belfast, and ${ }^{\#}$ Adult Cystic Fibrosis Unit, Belfast City Hospital, Belfast, Northern Ireland, UK.
\end{abstract}

Correspondence: L.T. McGrath, Dept of Therapeutics and Pharmacology, Whitla Medical Building, The Queen's University of Belfast, 97 Lisburn Road, Belfast BT9 7BL Northern Ireland, UK. Fax: 44 02890438346

Keywords: Breath isoprene

cystic fibrosis

free radicals

oxidative stress

Received: March 62000

Accepted after revision July 142000
The contribution of oxygen derived free radicals to the pathogenesis of many diseases is now generally accepted. These include atherosclerosis, cancer and post ischaemic reperfusion-induced injury [1-3]. Free radical species contain an unpaired electron and have the ability to damage biological macromolecules [4]. In biological systems the majority of free radicals are derived from dioxygen, e.g. the superoxide anion and the hydroxyl radical.

A major role for oxygen derived free radicals has been proposed in the damage to lung tissue found in cystic fibrosis (CF) [5]. The dominant source of free radicals found in the bronchi/alveoli is the accumulation of polymorphonuclear neutrophils (PMNs) associated with repeated cycles of infection and persistent inflammation. One of the mechanisms of action of the PMNs is the generation of radicals. While these are important in killing the pathogens they may damage the pulmonary epithelium by way of peroxidative destruction of the cell membrane [6].

There have always been problems in assessing free radical damage in vivo. This is a function of both the methodologies available and the fact that free radical tissue damage tends to be a highly compartmentalized process. The most widely used methods measure markers of lipid peroxidation (malondialdehyde (MDA)) or protein oxidation (protein carbonyls) in the systemic circulation [7]. A novel method of assessing free radical damage in real time by analysing exhaled breath, has used the properties of lipid hydroperoxides produced by free radical attack on polyunsaturated fatty acids.

Lipid hydroperoxides fragment to produce numerous degradation products. One of the products is believed to be the volatile isoprene (2-methyl-1,3 butadiene) which can be detected in breath [8]. The source of this compound, in addition to that contributed from the systemic circulation, will be directly from the fragmenting lipid hydroperoxides in the lung epithelia. This should avoid the problems associated with using a systemic marker to assess a compartmentalized process. Some doubts however, have been cast upon the validity of this compound as a marker of free radical activity [9]. It has demonstrated that the degree of oxidative stress in CF patients is related to the presence of acute respiratory exacerbation [10]. As part of the present study the authors have subsequently examined the production of isoprene to address the question, "Does breath isoprene content reflect systemic oxidative stress?"

\section{Materials and methods}

Study subjects and study design

Twelve patients with CF (eight males) and 12 healthy controls (nine males) were studied. Patients with CF had a 
prior diagnosis of CF by genotype and or sweat testing (sweat sodium concentration $>70 \mathrm{mmol} \cdot \mathrm{L}^{-1}$ ) and in vitro cultures of sputum showing chronic colonization by $\geq 1$ organisms associated with CF. All patients were receiving vitamin E supplementation $\left(200 \mathrm{mg} \cdot \mathrm{day}^{-1}\right)$. Patients were recruited at the time of symptomatic exacerbation of their lung disease defined as a reduction in forced expiratory volume in one second (FEV1) of $>10 \%$ compared to the best in the previous year, an increase in respiratory symptoms and a decision to treat with intravenous antibiotics. Samples were collected at the time of hospitalization before commencement of treatment and again following two weeks of antibiotic treatment. Control subjects had no personal or immediate family history of CF and no evidence of illness at the start of or during the trial. Controls were excluded if they were on any antimicrobial medication at the start of or at any time during the trial. The study was approved by the local ethics committee and informed consent was obtained from all participants prior to initiation of the protocol.

\section{Sample collection and treatment}

The sampling protocol was designed to minimize oxidation after collection of blood [11]. Twenty millilitres of venous blood was collected from resting, fasting subjects and prepared for the analysis of red cell membrane fatty acids, plasma MDA, carbonyls and protein thiols as previously described. All of these samples were stored at $-80^{\circ} \mathrm{C}$ and analysed within 4 weeks. Breath was collected via a two-way nonrebreathing valve into a $60 \mathrm{~L}$ gas collection bag. The subjects nose was clamped and the collection tubes equilibrated for 60 $\mathrm{s}$, the breath being vented to air via a three-way tap. The breath was then transferred into the collection bag and collected for $3 \mathrm{~min}$ and the volume recorded. A sample of ambient air was collected at the same time. A measured aliquot $(\sim 1.5 \mathrm{~L})$ of sample was drawn through a gas absorption tube packed with poropak- $\mathrm{Q}^{\mathrm{TM}}$. All samples of breath were collected at 10:00 h.

\section{Pulmonary function tests}

Measurements taken included, FEV1 and forced expiratory volume (FVC) using a vitalograph spirometer. These procedures were repeated in the patients at the end of the two-week period.

\section{Biochemical analyses}

MDA was determined by high performance liquid chromatography (HPLC) and total cholesterol enzymatically as previously described [12]. Total plasma sulphydryls and protein carbonyls were assayed spectrophotometrically $[13,14]$. Protein carbonyl results were expressed per gram of protein. The results of the MDA analyses were lipid standardized and expressed per mole of total cholesterol. Lipid was extracted from red blood cell membranes, saponified, derivatized with pentafluorobenzene and analysed by capillary gas chromatography (GC) with electron capture detection as previously described [15]. The percentage of the total fatty acids comprised of polyunsaturated fatty acids (PUFAs) was calculated from the individual fatty acids. This was expressed as moles per cent.

\section{Isoprene}

The absorbed organic breath contents were analysed for isoprene by thermal desorption GC mass spectrometry using the following procedure. The analytical system comprised a Perkin Elmer ATD 400 automated thermal desorption unit (Perkin Elmer, Norwalk, CT, USA), coupled to a Hewlett Packard 5890 GC (Hewlett Packard, Palo Alto, CA, USA) with a Restek RT $\times \% 30 \mathrm{~m}$ fused silica capillary column. The column was directly interfaced to a VG Trio bench-top mass spectrometer (VG Trio, Thermo VG, West Sussex, UK). The sample tubes were purged at $200^{\circ} \mathrm{C}$ for $10 \mathrm{~min}$ and the desorbed components collected on a cold trap packed with Tenax and maintained at $-30^{\circ} \mathrm{C}$. The cold trap was ballistically heated to $250^{\circ} \mathrm{C}$, which initiated the GC. The column was held at $40^{\circ} \mathrm{C}$ for 5 min and then heated at $10^{\circ} \mathrm{C} \cdot \mathrm{min}^{-1}$ to a final temperature of $280^{\circ} \mathrm{C}$. Isoprene, which eluted after $\sim 3 \mathrm{~min}$, was detected by monitoring the ion at $\mathrm{m} / \mathrm{z} 68$. Levels were quantified relative to toluene, which was introduced on to a tube by direct injection in methanol. The concentration of isoprene in breath was used to calculate the rate of production $\cdot \mathrm{min}^{-1}$. This was then related to body mass and expressed as $\mathrm{pmol} \cdot \mathrm{min} \cdot \mathrm{kg}^{-1}$.

\section{Statistical analyses an expression of results}

Data were analysed using the SPSS package (SPSS Inc., Chicago, Il, USA). Comparisons between the two groups (patients during exacerbation and controls) were made using the Mann-Whitney rank sum test and comparisons between patients before and after treatment were made using Wilcoxon's matched pairs signed ranks test. Absolute values are summarized in tables 1-2 and expressed as mean \pm SE. The mean differences between patients and controls and mean changes within the patient group following treatment are given with $95 \%$ confidence intervals (CI) for the difference/change. A p-value of $\leq 0.05$ was considered significant.

\section{Results}

\section{Subjects}

The average age of patients was 25 yrs (range 22.4 27.7) and of the controls was 24.9 yrs (range 23.8-6.0). Of the patients, $7(58 \%)$ were chronically colonized by Burkholderia cepacia while $5(42 \%)$ were chronically colonized with Pseudomonas aeruginosa.

\section{Clinical markers}

Absolute mean \pm SEM levels of the clinical markers in patients and the controls are summarized in table 1. During acute respiratory exacerbation the patients had a significantly lower FEV1 $(1.60 \pm 0.30) \mathrm{L})$ than the controls (4.43 \pm 0.30$)$, mean difference -2.82 L (95\% CI 2.12-3.52) 
Table 1. - Values for pulmonary function tests and inflammatory markers in patients during exacerbation and after antibiotic treatment and controls

\begin{tabular}{lccc}
\hline & \multicolumn{2}{c}{ CF patients } & Controls \\
\cline { 2 - 4 } & Exacerbation & Post-treatment & \\
\hline FEV1 L & $1.6 \pm 0.3^{*}$ & $1.89 \pm 0.3^{*,+, *^{*}}$ & $4.43 \pm 0.3$ \\
FVC L & $2.37 \pm 0.35^{*,+}$ & $2.70 \pm 0.40^{*,+,{ }^{*}}$ & $5.16 \pm 0.30$ \\
\hline
\end{tabular}

Values are expressed as mean \pm SEM FEV1: forced expiratory volume in one second; FVC: forced vital capacity; CF: cystic fibrosis. *: $\mathrm{p}<0.05 ; * *$ : $<<0.01 ;^{+}$: versus control; ${ }^{\#}$ : versus value during exacerbation. $\mathrm{n}=12$ for both patients and controls.

$\mathrm{L}(\mathrm{p}<0.05)$. Similarly, FVC was lower in the patients than in the controls $(2.37 \pm 0.35$ versus $5.16 \pm 0.30)$, mean difference -3.79 L $(95 \%$ CI 3.03-4.55) L $(\mathrm{p}<0.05)$. Both FEV1 and FVC increased significantly in the patients following treatment $(\mathrm{FEV} 11.89 \pm 0.30) \mathrm{L}$, mean change $0.29(95 \%$ CI $0.18-0.40)$ L, FVC $2.70 \pm 0.40$ L, mean change $0.33 \mathrm{~L}(0.23-0.43) \mathrm{L}$; both $\mathrm{p}<0.05)$. The values remained lower than in controls $(\mathrm{p}<0.05)$.

\section{Markers of free radical damage and total cholesterol}

These are summarized in table 2. Total protein sulphydryls were significantly lower in patients during infection than in controls $(299 \pm 59$ versus $421 \pm 75)$, mean difference $\left.-122(95 \% \mathrm{CI}-77-167) \mu \mathrm{mol} \cdot \mathrm{L}^{-1}, \mathrm{p}<0.005\right)$ and increased significantly after treatment to $349 \pm 55$ $\mu \mathrm{mol} \cdot \mathrm{L}^{-1}$ (mean change $50(32-68) \mu \mathrm{mol} \cdot \mathrm{L}^{-1}, \mathrm{p}<0.01$ ). They continued to remain lower than the levels in control subjects, although they were not statistically significant. Lipid standardized MDA was higher during respiratory exacerbation than in control subjects $(362 \pm 136$ versus $169 \pm 24$, mean difference 193 (107-279) nmol. $\mathrm{mmol}^{-1}$ cholesterol, $\mathrm{p}<0.05)$ and remained high following treatment $\left(306 \pm 73 \mathrm{nmol} \cdot \mathrm{mmol}^{-1}\right.$ cholesterol) compared with controls $(\mathrm{p}<0.05)$. MDA levels decreased following treatment (mean difference -56 (-28-84) but this change did not reach significance. There was no change between the two observations in patient subjects. Protein carbonyl concentrations during respiratory exacerbation were not significantly different from control subjects $(0.58 \pm 0.14$ versus $0.53 \pm 0.14 \mu \mathrm{mol} \cdot \mathrm{g}$ protein $\left.^{-1}\right)$ but increased after treatment $\left(0.97 \pm 0.37 \mu \mathrm{mol} \cdot \mathrm{g}\right.$ protein $\left.{ }^{-1}\right)$ to become significantly higher than during exacerbation (mean change $0.39(0.11-0.67) \mu \mathrm{mol} \cdot \mathrm{g}$ protein $\left.{ }^{-1}, \mathrm{p}<0.05\right)$. They were also higher than the levels in control subjects (mean difference $\left.0.44(0.14-0.74) \mu \mathrm{mol} \cdot \mathrm{g}^{-1}, \mathrm{p}<0.005\right)$. The percentage of PUFAs in red cell membranes of the patients was lower during respiratory exacerbation than in control subjects $(35.0 \pm 8.2)$ versus $39.4 \pm 4.7$, mean difference $-4.4(-2.6-6.2)$ moles per cent, $\mathrm{p}<0.01)$. PUFAs did not increase with treatment. PUFAs remained lower after treatment (26.7-46.3 moles per cent, mean difference 2.9 moles per cent, $\mathrm{p}<0.05$ ) compared to controls and were not different from baseline.

\section{Isoprene}

This is summarized in table 2. Breath isoprene was significantly lower in patients during acute respiratory exacerbation than in controls $(125 \pm 23$ versus $164 \pm 20$, mean difference $\left.-39 \quad(-11-57) \mathrm{pmol} \cdot \mathrm{min} \cdot \mathrm{kg}^{-1}, \mathrm{p}<0.05\right)$ and increased significantly after treatment to $188 \pm 23$ $\mathrm{pmol} \cdot \mathrm{min} \cdot \mathrm{kg}^{-1}$ (mean change 63 (42-84) $\mathrm{pmol} \cdot \mathrm{min} \cdot \mathrm{kg}^{-1}$, $\mathrm{p}<0.05)$.

\section{Discussion}

Free radicals are produced constantly by normal metabolic pathways. A major group of free radicals, the reactive oxygen species (ROS), are derived from molecular oxygen and include the superoxide anion $\left(\mathrm{O}_{2}{ }^{-}\right)$, hydrogen peroxide $\left(\mathrm{H}_{2} \mathrm{O}_{2}\right)$ and the hydroxyl radical $\left(\mathrm{OH}^{-}\right)$[4]. The $\mathrm{OH}^{-}$ radical in particular has the potential to cause structural damage to lipids, proteins, carbohydrates and nucleic acids. Whether or not they produce damage is determined by the balance between their generation and the bodies antioxidant capacity [16]. A major source of free radicals are the mitochondria and activated phagocytes [17]. This is particularly relevant to CF patients who show evidence of depleted antioxidant capacity, increased systemic radical generation secondary to leakage of electrons from increased electron transport activity and extensive production from activated neutrophils in the lung in response to infection $[5,18,19]$. It is obvious that an ability to follow the course and extent of free radical

Table 2. - Aqueous phase antioxidant, markers of free radical damage in the plasma and isoprene in the breath of patients during exacerbation and after antibiotic treatment and controls

\begin{tabular}{|c|c|c|c|}
\hline & \multicolumn{2}{|c|}{ CF patients } & \multirow{2}{*}{ Controls } \\
\hline & Exacerbation & Post-treatment & \\
\hline Sulphydryls $\mu \mathrm{mol} \cdot \mathrm{L}^{-1}$ & $299 \pm 59 * * *,+$ & $349 \pm 55^{* *, \#}$ & $421 \pm 75$ \\
\hline MDA nmol $\cdot \mathrm{mmol}^{\text {cholesterol }^{-1}}$ & $362 \pm 136^{*,+}$ & $306 \pm 73 *{ }^{+}$ & $169 \pm 24$ \\
\hline Protein carbonyls $\mu \mathrm{mol} \cdot \mathrm{g}$ protein ${ }^{-1}$ & $0.58 \pm 0.14$ & $0.97 \pm 0.37^{*,+, * * *, \#}$ & $0.53 \pm 0.14$ \\
\hline PUFAs Moles per cent & $35.0 \pm 8.2^{*} *,^{+}$ & $36.5 \pm 4.9^{*,+}$ & $39.4 \pm 4.7$ \\
\hline Isoprene $\mathrm{pmol} \cdot \mathrm{min} \cdot \mathrm{kg}^{-1}$ & $125 \pm 23^{*,+}$ & $188 \pm 23^{*, \#}$ & $164 \pm 20$ \\
\hline
\end{tabular}

Values are expressed as mean \pm standard error. MDA: malondialdehyde; PUFAs: polyunsaturated fatty acids; CF: cystic fibrosis. *: $\mathrm{p}<0.05 ; * *: \mathrm{p}<0.01 ; * * *: \mathrm{p}<0.005 ;^{+}$: versus control; ${ }^{\#}$ : versus first patient observation. 
mediated damage in a disorder such as CF would be a useful clinical tool. The utility of using a volatile marker of free radical damage (isoprene) was examined in the breath of CF patients by comparing it with conventional measures of free radical damage/activity. Patients were studied at a time of maximum oxidative stress during a period of acute respiratory exacerbation and again following two weeks treatment when oxidative stress would be expected to have abated. During acute exacerbation markers including plasma MDA, plasma protein thiols and red cell membrane PUFAs provided evidence of increased oxidative stress. This degree of oxidative stress decreased following antibiotic treatment although it did not reach normal levels. Levels of protein carbonyls increased after treatment. This may reflect different kinetics for damage to proteins and their appearance in the systemic circulation. In contrast to other workers who found increased breath isoprene in conditions associated with increased oxidative stress to lung epithelia the authors found decreased levels during acute respiratory exacerbation which increased towards normal, following treatment [20].

The ability to assess free radical damage/activity has always been compromised by limitations in the assays available. One approach has been to assess peroxidative damage to lipids. This has been assessed, most commonly, by measuring MDA, a break down product of lipid hydroperoxides. Original methods depended upon the reaction with thiobarbituric acid. The original nonspecific method measuring thiobarbituric acid reacting substances (TBARS) has been replaced by methods specific for MDA [21]. Analysing the fatty acid composition of red blood cell membranes may assess peroxidation of membrane phospholipid PUFAs. Consumption of PUFAs is evidence of peroxidative damage.

An alternative approach has been to examine the effect on proteins by measuring protein carbonyls [14]. In addition to these direct measurement methods, free radical activity has been assessed indirectly by measuring the consumption of scavengers. Proteins can scavenge free radicals by donating a hydrogen atom from sulphydryl side chains. Evidence of increased scavenging is provided by a reduction in reduced protein thiols [13].

A major draw back of these assays is that they reflect total activity and cannot address the question of the site of origin. This could be addressed by examining bronchiolar ravage for evidence of free radical activity. The membrane of small airway epithelial cells is a major target for free radical damage in these patients, another possible alternative would be to examine a volatile derivative of peroxidized membrane lipids. Measurement of a volatile compound in breath partially meets these conditions in that it is produced directly from the lung surface. This is confounded by the fact that an unquantifiable fraction comes from the systemic circulation.

Measurement of a volatile compound in breath to assess oxidative stress has been used in a number of conditions. Originally pentane was measured as the volatile compound. LeMOYNE et al. [22] analysed breath pentane to demonstrate the ability of supplemental vitamin $\mathrm{E}$ to reduce oxidative stress. Levels of breath pentane were inversely proportional to vitamin E levels. VAN Gossum et al. [23] infused lipid rich in linoleic acid into individuals and demonstrated increased breath pentane. Hotz et al.
[24] demonstrated small increases in breath pentane in cirrhotic patients. Many of the methodologies employed GC to analyse breath. KoHLmuller and Kochen [25] carried out an analysis of these methods and found them to have unacceptable limitations, either relating to sensitivity or specificity. They developed a gas chromatographic/mass spectroscopic (GC/MS) method. This showed that using the common GC methods, the "npentane" peak was actually composed predominantly of isoprene and these previous studies had misidentified the compound. The method employed in this study was a specific GC/MS method with confirmation of the peak as isoprene. Analysis of breath isoprene has inherent difficulties apart from the methodology, these include a wide distribution within and between individuals, a distinct circadian rhythm and dependence on the state of nutrition and exercise [26, 27]. In an effort to minimize variations all of the subjects in the present study were closely matched, sampled fasting at the same time of day, and were resting. To minimize variations in concentration due to rate and depth of breathing, breath isoprene was calculated as a production rate in mass eliminated per $\mathrm{kg}$ of body mass per unit of time rather than as an absolute concentration. This does not resolve the problem encountered in the present study that breath isoprene decreased during the period of maximum oxidative stress and increased towards normal following treatment which would be expected to diminish oxidative stress [28]. This raises the possibility that isoprene either does not track, or is indirectly related to, oxidative stress. The observed results may also be partly explained by altered transmission/diffusion properties of the lung membranes. During periods of acute respiratory exacerbation transmission of isoprene from systemic sources may be reduced. This could lower breath concentration even in the presence of increased systemic production. Improvement due to treatment transmission could increase. This process should have a smaller impact on isoprene generated from lung epithelial membranes. Isoprene from this source would be released directly into the lung space, although this could also be inhibited by mucus accumulation. The work of SCHUBERT et al. [29] is interesting in this respect. While they demonstrated a decrease in breath isoprene in critically ill patients who developed pulmonary infection, breath pentane actually increased. These conflicts can only be resolved by measuring isoprene in blood. The exact origin of isoprene in human breath is not known. KoHLmuller and Kochen [25] argue that polyisoprenes, e.g. squalene, are possible sources of isoprene via a radically mediated in vivo peroxidation. Mechanisms which induce an increased rate of reactive oxygen intermediates and are thought to attack membrane PUFAs might also attack polyisoprenes with the consequence that isoprene and n-pentane are produced.

Alternatively STONE et al. [9] have suggested that isoprene might also be produced from mevalonate as a by-product of cholesterol synthesis. They provided evidence to support this hypothesis by manipulating cholesterol synthesis in human volunteers and comparing breath isoprene with rate of cholesterol synthesis. In the present study lowest levels of breath isoprene were found during acute exacerbation, the period of highest oxidative stress. When this had been modified by antibiotic treatment levels of cholesterol increased, although not 
significantly, markers of oxidative stress decreased and breath isoprene increased towards normal. Animal studies have shown that endotoxin, tumour necrosis factor and interleukin decrease hepatic squalene synthase messenger ribonucleic acid, activity and protein mass [30]. This would reduce the production of isoprene. The present results do not support the hypothesis that breath isoprene can be used as a reliable real time marker of oxidative stress.

\section{References}

1. Munro JM, Cotran RS. The pathogenesis of atherosclerosis: atherogenesis and inflammation. Lab Invest 1988; 58: 249-253.

2. Ames BN. Endogenous oxidative DNA damage, ageing and cancer. Free Radical Res Commun 1989; 7: 121-128.

3. McMurlan MA, Tomkins AM, Garlick PJ. The effect of starvation on the rate of protein synthesis in the rat liver and small intestine. Biochem J 1979; 178: 373-379.

4. Rice-Evans CA, Diplock AT, Symons MCR. Techniques in free radical research. In: Burdon RH, Knippenberg $\mathrm{PH}$, eds. Laboratory Techniques in Biochemistry and Molecular Biology. London, Elsevier, 1991; pp. 1-18.

5. Salh B, Webb K, Guyan PM, Day JP, Wickers D, Griffin J. Aberrant free radical activity in cystic fibrosis. Clin Chim Acta 1989; 181: 65-74.

6. Davis PBO. Pathophysiology of the lung disease in cystic fibrosis. In: Davis PB, ed. Cystic Fibrosis. New York, Marcel Dekker Inc., 1993; pp. 193-218.

7. Reilly PM, Schiller HJ, Bulkley GB. Pharmacologic approach to tissue injury mediated by free radicals and other reactive oxygen metabolises. Am J Surg 1991; 161: 488-503.

8. Kohlmuller D, Kochen W. Is n-pentane really an index of of lipid peroxidation in humans and animals? A methodological reevaluation. Anal Biochem 1993; 210: 268-276.

9. Stone BG, Besse TJ, Duane WC, Evans CD, DeMaster EG. Effect of regulating cholesterol biosynthesis on breath isoprene excretion in men. Lipids 1993; 28: 705708.

10. McGrath LT, Mallon P, Dowey L, et al. Oxidative stress during acute respiratory exacerbations in cystic fibrosis. Thorax 1999; 54: 518-523.

11. Slater TF. Overview of methods used for detecting lipid peroxidation. Methods Enymol 1984; 105: 283-293.

12. McGrath LT, Douglas AF, McClean E, et al. Oxidative stress and erythrocyte membrane fluidity in patients undergoing regular dialysis. Clin Chim Acta 1995; 235: 179-188.

13. Brown RK, Kelly FJ. Evidence for increased oxidative damage in patients with cystic fibrosis. Pediatr Res 1994; 36: 487-493.

14. Levine RL, Garland D, Oliver $\mathrm{CN}$, et al. The determination of carbonyl content in oxidatively modified proteins. In: Packer L, Glaver AN, eds. Methods in Enzymology, Vol 186. London, Academic Press, 1990; pp. 464-477.

15. McGrath LT, Elliott RJ. Lipid analysis and fatty acid profiles of individual atherosclerotic plaques. Anal Biochem 1990; 187: 273-276.

16. Reilly PM, Schiller HJ, Bulkley GB. Pharmacologic approach to tissue injury mediated by free radicals and other reactive oxygen metabolises. Am J Surg 1991; 161: 488-503.

17. Porter NA. Chemistry of lipid peroxidation. Methods Enzymol 1984; 1105: 273-283.

18. Feigal R1, Shapiro BL. Mitochondrial calcium uptake and oxygen consumption in cystic fibrosis. Nature 1979; 278: 276-277.

19. Holsclaw DS. Cystic fibrosis and pulmonary involvement from multiple perspectives. Semin Respir Infect 1993; 7 : 141-150.

20. Foster WM, Jiang L, Stetkiewicz PT. Breath isoprene: temporal changes in respiratory output after exposure to ozone. J Appl Physiol 1996; 80(2): 706-710.

21. Gorog P, Kotak DC, Kovacs IB. Simple and specific test for measuring lipid peroxides in plasma. $J$ Clin Pathol 1991; 44: 765-767.

22. Lemoyne M, Van Gossum A, Kurian R, Ostro M, Axler J, Jeejeebhoy KN. Breath pentane analysis as an index of lipid peroxidation: a functional test of vitamin $\mathrm{E}$ status. Am J Clin Nutr 1987; 46: 267-272.

23. Van Gossum A, Shariff R, Lemoyne M, Kurian RT, Jeejeebhoy K. Increased lipid peroxidation after lipid infusion as measured by breath pentane output. Am J Clin Nutr 1988; 48: 1394-1399.

24. Hotz P, Hoet P, Lanwerys R, Buchet J-P. Development of a method to monitor low molecular mass hydrocarbons in exhaled breath of man: preliminary evaluation of its interest for detecting a lipoperoxidation process in vivo. Clinica Chimica Acta 1987; 162: 303-310.

25. Kohlmuller D, Kochen W. Is n-pentane really an index of lipid peroxidation in humans and animals? A methodological reevaluation. Anal Biochem 1993; 210: 268-276.

26. Spanel P, Davies S, Smith D. Quantification of breath isoprene using the selected ion flow tube mass spectrophotometric analytical method. Rapid Commun Mass Spectrom 1999; 17: 1733-1738.

27. Hyspler R, Crhová S, Gasparic J, Zadák Z, Cinodotzková M, Balasová V. Determination of isoprene in human expired breath using solid-phase microextraction and gas chromatography-mass spectrometry. $J$ Chromatogr $B$ 2000; 739: 183-190.

28. Meyer KC, Lewandoski JR, Zimmerman JJ, Nunley D, Calhoun WJ, Dopico GA. Human neutrophil and elastase/ alpha 1antiprotease complex in cystic fibrosis. Comparison with interstitial lung disease and evaluation of the effect of intravenously administered antibiotic therapy. Am Rev Respir Dis 1991; 144: 580-585.

29. Schubert JK, Müller WP, Benzing A, Geiger K. Application of a new method for analysis of exhaled gas in critically ill patients. Intensive Care Med 1998; 5: 415-421.

30. Memon RA, Schecter I, Moser AH, Shigenaga JK, Grunfeld C, Feingold KR. Endotoxin, tumour necrosis factor, and interleukin-1 decrease hepatic squalene synthase activity, protein, and mRNA levels in Syrian hamsters. J Lipid Res 1997; 38(8): 1620-1629. 